\title{
Characterization of Basidiomycetes Associated with Wood Rot of Citrus in Southern Italy
}

\author{
Angela Roccotelli, Leonardo Schena, Simona M. Sanzani, Santa O. Cacciola, Saveria Mosca, \\ Roberto Faedda, Antonio Ippolito, and Gaetano Magnano di San Lio
}

First, second, fifth, and eighth authors: Dipartimento di Agraria, Università degli Studi Mediterranea, Località Feo di Vito, 89122 Reggio Calabria, Italy; third and seventh authors: Dipartimento di Scienze del Suolo, della Pianta e degli Alimenti, Università degli Studi "Aldo Moro", Via Amendola 165/A, 70126 Bari, Italy; and fourth and sixth authors: Dipartimento di Gestione dei Sistemi Agroalimentari e Ambientali, Università degli Studi, Via Santa Sofia, 100, 95123 Catania, Italy. Accepted for publication 24 January 2014.

\begin{abstract}
Roccotelli, A., Schena, L., Sanzani, S. M., Cacciola, S. O., Mosca, S., Faedda, R., Ippolito, A., and Magnano di San Lio, G. 2014. Characterization of basidiomycetes associated with wood rot of citrus in southern Italy. Phytopathology 104:851-858.

The characterization of Basidiomycetes associated with wood rots in commercial citrus orchards in southern Italy revealed that both white and brown rot fungi are implicated in this disease. Fomitiporia mediterranea was the most prevalent species causing a white rot, followed by Fomitopsis sp. which, by contrast, was associated with brown rot wood decay. Furthermore, Phellinus spp. and other nonidentified basidiomycetous fungi showing genetic affinity with the genera Phellinus and Coniophora were occasionally isolated. Artificial inoculations on lemon

sp. compared with $F$. mediterranea, indicating that the former species as a potentially serious pathogen of citrus trees. The analysis of $F$. mediterranea internal transcribed spacer (ITS) sequences revealed a high level of genetic variability, with 13 genotypes which were both homozygous (6 genotypes) and heterozygous (7 genotypes). The presence of heterozygous genomes based on ITS sequences has never been reported before for F. mediterranea. This, together with the high frequency of basidiomata on infected wood, unambiguously confirms the outcrossing nature of reproduction in F. mediterranea and the primary role of basidiospores in the dissemination of inoculum. Similarly, high genetic variability was observed analyzing Fomitopsis sp. Because basidiomata of this fungus have not been observed on citrus trees, it can be hypothesized that basidiospores are produced on alternative host plants.
\end{abstract} (Citrus limon) branches showed a faster wood colonization by Fomitopsis
Wood rot diseases are caused by a wide variety of specialized fungi and are characterized by decay and discoloration of wood of the trunk, large branches, and roots of practically all woody plants. Most wood-degrading microorganisms are basidiomycetous fungi that, on living trees, can cause two major kinds of decay: brown and white rots (3). Although wood decay fungi play an ecologically important role as primary biotic decomposers of wood in forest ecosystems, they can cause economic losses in cultivated orchards by contributing to the premature aging and the structural failure of the trees $(6,28)$. Most wood decay fungi penetrate through wounds, although a few of the root-infecting species can enter the unwounded surface directly.

Citrus wood rot is a chronic disease occurring endemically and rather frequently on old trees in most citrus-growing areas of the world $(4,5,8)$. Although this disease is not a major constraint for the citrus industry, it can contribute to the deterioration of orchards because affected trees show a premature aging, a progressive decline in vigor, and reduced productivity. A direct effect of wood decay is the breakage of scaffold branches due to loss of wood strength. Moreover, extended infections of wood rot in the trunk hinder old citrus trees from being top worked. It is assumed that most infections in citrus orchards originate from airborne basidiospores germinating on pruning wounds, although limited information is currently available on the biology and ecology of the causal agents. Other injuries, such as bark cracks caused by

Corresponding author: L. Schena; E-mail address: 1schena@unirc.it

http://dx.doi.org/10.1094/PHYTO-10-13-0272-R

(c) 2014 The American Phytopathological Society frost, sunscald areas on main scaffold branches, or splitting of limbs as a result of heavy fruit load, are other potential infection courts (29).

Environmental factors have major effects not only on disease onset and development but also on the expression of symptoms. During the hot and dry summer season, the breaking of woody organs as well as leaf wilt, chlorosis, and defoliation on affected branches occur, whereas rainy and warm weather favor the enlargement of bark cankers, the production of basidiocarps on the cankers, and the progression of inner wood rot. In addition, the disease incidence seems to be correlated with the intensity and pattern of precipitation. Among intrinsic characteristics of the host, age and variety of citrus have a major role in the manifestation of the disease. The incidence of the disease is higher in old orchards and on susceptible species and cultivars. In particular, lemon (Citrus limon) trees were reported to be significantly more susceptible to wood decay than other types of citrus, including orange, grapefruit, and tangelo $(5,22,31)$. In Sicily, sweet orange (C. sinensis) 'Ovale' and 'Moro' appeared more susceptible than 'Tarocco' and 'Valencia' whereas, in Apulia, southern Italy, the clementine 'Fedele' was reported to be very susceptible $(21,22)$. By contrast, the sour orange ( $C$. aurantium) rootstock seems to be tolerant to natural infections $(15,22)$. Moreover, the type of rootstock does not seem to affect the susceptibility of the scion (5).

Although early reports of citrus wood rot date back to the first half of the last century (36), the etiology of the disease has not yet been clearly defined because it is very complex and variable according to the locality. The causal agent of a wood rot and canker of living citrus trees, a disease which was reported quite commonly in Florida, was tentatively identified as Fomes ap- 
planatus, currently synonymous with Ganoderma applanatum (8). However, two types of basidiocarps were shown and described: woody shelf-like perennial conks, typical of this species, and resupinate conks (8). Although this latter type was considered a variant by the author, it is very distinct from the shelf-like type and can be unambiguously referred to Fomitiporia spp. Other reports indicate $G$. sessilis, currently synonymous with $G$. lucidum, as a fungal agent invading the wood of living trees in Florida (26). The same fungus was later reported on 'Marrs' early orange, 'Cleopatra' mandarin, and 'Swingle' citrumelo in South Texas $(43,44)$. More recently, G. applanatum was found on citrus stumps in Florida (19). Antrodia sinuosa, Coniophora eremophila, and a species of Nodulisporium were identified as the causal agents of brown heartwood rot of lemon in Arizona (5,31). As far as Europe is concerned, Fomitiporia mediterranea has been reported as the most common citrus wood-rotting fungus in Italy (22) and Greece (15).

The aim of the present study was to characterize lignicolous basidiomycetes associated with wood rots in commercial citrus orchards of southern Italy in order to provide a better insight into their ecology and to define their role in the etiology of the disease.

\section{MATERIALS AND METHODS}

Samplings. Fruiting bodies of lignicolous fungi and symptomatic wood samples were collected over a 3-year period (2010 to 2012) during field surveys in citrus orchards of variable age located in two different regions (Apulia and Sicily) in southern Italy (Table 1). Fruiting bodies were mostly collected in Sicily

TABLE 1. Isolates of lignicolous fungi analyzed in the present study, their origin, colony type and genotypes, and alleles as determined by the analysis of internal transcribed spacer (ITS) sequences.

\begin{tabular}{|c|c|c|c|c|c|c|c|}
\hline \multirow[b]{2}{*}{ Isolate $^{\mathrm{v}}$} & \multicolumn{3}{|c|}{ Source trees } & \multirow[b]{2}{*}{ Colony ${ }^{x}$} & \multirow[b]{2}{*}{ Genotype $^{y}$} & \multirow[b]{2}{*}{ Allele } & \multirow[b]{2}{*}{ Accession $^{\mathrm{Z}}$} \\
\hline & Species, cultivar & Origin & $\mathrm{Age}^{\mathrm{w}}$ & & & & \\
\hline \multicolumn{8}{|c|}{ Fomitiporia mediterranea } \\
\hline F1 (w) & Clementine, Comune & Palagiano (Apulia) & 40 & $\mathrm{~B}$ & G1 & a1 & 08 \\
\hline F2 (w) & Clementine, Comune & Palagiano (Apulia) & 40 & $\mathrm{~B}$ & G1 & a1 & 09 \\
\hline F3 (w) & Clementine, Comune & Palagiano (Apulia) & 40 & $\mathrm{~B}$ & G1 & a1 & 10 \\
\hline F5 (w) & Clementine, Comune & Palagiano (Apulia) & 40 & $\mathrm{~B}$ & G1 & a1 & 11 \\
\hline F6 (w) & Clementine, Comune & Palagiano (Apulia) & 40 & B & G2 & $\mathrm{a} 2$ & 26 \\
\hline F7 (w) & Clementine, Comune & Palagiano (Apulia) & 40 & $\mathrm{~B}$ & G1 & a1 & 12 \\
\hline F8 (w) & Clementine, Comune & Palagiano (Apulia) & 40 & $\mathrm{~B}$ & G1 & a1 & 13 \\
\hline F9 (w) & Clementine, Comune & Palagiano (Apulia) & 40 & $\mathrm{~B}$ & G1 & a1 & 14 \\
\hline $\mathrm{F} 10(\mathrm{w})$ & Clementine, Comune & Palagiano (Apulia) & 40 & $\mathrm{~B}$ & G1 & a1 & 15 \\
\hline F11 (w) & Clementine, Comune & Palagiano (Apulia) & 40 & $\mathrm{~B}$ & G1 & a1 & 16 \\
\hline F12 (w) & Clementine, Comune & Palagiano (Apulia) & 40 & $\mathrm{~S}$ & G3 & $\mathrm{a} 3$ & 27 \\
\hline F14 (w) & Clementine, Comune & Palagiano (Apulia) & 40 & $\mathrm{~S}$ & $\mathrm{G} 1$ & a1 & 17 \\
\hline F15 (w) & Clementine, Comune & Palagiano (Apulia) & 40 & $\mathrm{~B}$ & G1 & a1 & 18 \\
\hline F16 (w) & Clementine, Comune & Palagiano (Apulia) & 40 & $\mathrm{~B}$ & $\mathrm{G} 1$ & a1 & 19 \\
\hline F17 (w) & Clementine, Comune & Palagiano (Apulia) & 40 & $\mathrm{~S}$ & G1 & a1 & 20 \\
\hline F18 (w) & Clementine, Comune & Palagiano (Apulia) & 40 & $\mathrm{~B}$ & G4 & $\mathrm{a} 1, \mathrm{a} 2, \mathrm{a} 4$ & $28,29,30$ \\
\hline F23 (w) & Clementine, Comune & Palagiano (Apulia) & 40 & $\mathrm{~B}$ & $\mathrm{G} 1$ & a1 & 21 \\
\hline F24 (w) & Clementine, Fedele & Castellaneta (Apulia) & 40 & $\mathrm{~S}$ & G5 & $\mathrm{a} 5, \mathrm{a} 6, \mathrm{a} 7, \mathrm{a} 8$ & $31,32,33,34$ \\
\hline $\mathrm{F} 27(\mathrm{fb})$ & Orange, Tarocco & Augusta (Sicily) & 40 & $\mathrm{~B}$ & G6 & a1, a9 & 35,36 \\
\hline F31 (fb) & Orange, Tarocco & Augusta (Sicily) & 40 & $\mathrm{~B}$ & $\mathrm{G} 7$ & $\mathrm{a} 10, \mathrm{a} 11$ & 41,42 \\
\hline $\mathrm{F} 32(\mathrm{fb})$ & Lemon & Augusta (Sicily) & 40 & $\mathrm{~B}$ & G8 & a1, a12 & 43,44 \\
\hline F33 (fb) & Orange, Ovale & Carlentini (Sicily) & 50 & $\mathrm{~S}$ & G9 & a13, a14 & 45,46 \\
\hline F34 (fb) & Orange, Ovale & Augusta (Sicily) & 60 & $\mathrm{~S}$ & G6 & a1, a9 & 37,38 \\
\hline $\mathrm{F} 35(\mathrm{fb})$ & Orange, Moro & Carlentini (Sicily) & 60 & $\mathrm{~S}$ & G1 & a1 & 22 \\
\hline $\mathrm{F} 38(\mathrm{fb})$ & Orange, Moro & Carlentini (Sicily) & 50 & $\mathrm{~S}$ & G6 & $\mathrm{a} 1, \mathrm{a} 9$ & 39,40 \\
\hline $\mathrm{F} 41(\mathrm{fb})$ & Orange, Moro & Carlentini (Sicily) & 50 & $\mathrm{~S}$ & $\mathrm{G} 1$ & a1 & 23 \\
\hline $\mathrm{F} 42(\mathrm{fb})$ & Lemon & Augusta (Sicily) & 40 & $\mathrm{~B}$ & G10 & $\mathrm{a} 15, \mathrm{a} 16$ & 47,48 \\
\hline $\mathrm{F} 44(\mathrm{fb})$ & Orange, Ovale & Carlentini (Sicily) & 50 & $\mathrm{~S}$ & G11 & a17 & 49 \\
\hline F149 (w) & Clementine, Monreal & Palagiano (Apulia) & 50 & n.d. & G12 & a18 & 50 \\
\hline F157 (fb) & Clementine, Spinoso & Palagiano (Apulia) & 50 & n.d. & G13 & a19 & 51 \\
\hline F159 (w) & Clementine, Spinoso & Palagiano (Apulia) & 50 & n.d. & G1 & a1 & 24 \\
\hline $\mathrm{Fk}(\mathrm{w})$ & Olive & Carlentini (Sicily) & 50 & $\mathrm{~S}$ & G1 & a1 & 25 \\
\hline \multicolumn{8}{|c|}{ Fomitopsis sp. } \\
\hline Fol (w) & Orange, Valencia late & Castellaneta (Apulia) & 40 & n.d. & G1 & n.d. & 51 \\
\hline Fo3 (w) & Orange, Valencia late & Castellaneta (Apulia) & 40 & n.d. & $\mathrm{G} 2$ & n.d. & 52 \\
\hline Fo4 (w) & Orange, Valencia late & Castellaneta (Apulia) & 40 & n.d. & G3 & n.d. & 53 \\
\hline Fo2 (w) & Orange, Valencia late & Castellaneta (Apulia) & 40 & n.d. & G4 & n.d. & 54 \\
\hline Fo6 (w) & Orange, Valencia late & Castellaneta (Apulia) & 40 & n.d. & G4 & n.d. & 55 \\
\hline Fo5 (w) & Orange, Valencia late & Castellaneta (Apulia) & 40 & n.d. & G5 & n.d. & 56 \\
\hline \multicolumn{8}{|c|}{ Phellinus-like isolates } \\
\hline P19 (w) & Clementine, Fedele & Castellaneta (Apulia) & 15 & n.d. & G1 & n.d. & 58 \\
\hline P20 (w) & Clementine, Fedele & Castellaneta (Apulia) & 15 & n.d. & G1 & n.d. & 59 \\
\hline P21 (w) & Clementine, Fedele & Castellaneta (Apulia) & 15 & n.d. & G1 & n.d. & 60 \\
\hline \multicolumn{8}{|c|}{ Phellinus sp. } \\
\hline $\mathrm{P} 173(\mathrm{fb})$ & Clementine, Fedele & Massafra (Apulia) & 40 & n.d. & G1 & n.d. & 57 \\
\hline \multicolumn{8}{|c|}{ Coniophora-like isolates } \\
\hline $\mathrm{C} 1(\mathrm{w})$ & Clementine, Fedele & Palagiano (Apulia) & 20 & n.d. & G1 & n.d. & 61 \\
\hline
\end{tabular}

${ }^{\mathrm{v}}$ Fungal isolates were obtained from symptomatic wood (w) or fruiting bodies (fb).

w Tree age expressed in years.

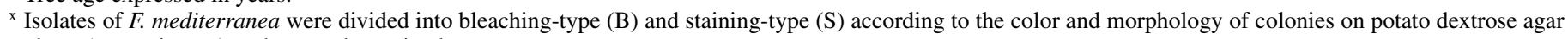
plates (see main text); n.d. = not determined.

y Genotype numbers refer to each identified taxon.

${ }^{z}$ GenBank accession numbers for sequences are KF615708 to KF615761; the last two numbers are listed for each isolate in the table. 
from old orchards while wood samples were sourced in Apulia, where fructifications of lignicolous fungi were very rare. Woody samples were mainly collected during the pruning of orchards and consisted of pieces of wood $(\approx 1 \mathrm{~kg})$ with symptoms of rot from trunks or large branches.

Isolation of lignicolous fungi. To isolate the potential causal agents of wood rot, samples were aseptically fractioned and small fragments of wood $\left(\approx 2 \mathrm{~mm}^{3}\right)$ were removed from symptomatic and surrounding areas to be plated on potato dextrose agar (PDA). In the case of fruiting bodies, external tissues were aseptically discarded and small pieces of internal tissues $\left(\approx 1 \mathrm{~mm}^{3}\right)$ were transferred onto PDA. In both cases, PDA was amended with streptomycin $(250 \mathrm{mg} / \mathrm{liter})$ to prevent the growth of bacteria. Plates were incubated at $24^{\circ} \mathrm{C}$ in the dark for 5 to 10 days and all colonies resembling those of basidiomycetous fungi were transferred onto new PDA plates. All fungal isolates were stored on PDA slants at $5^{\circ} \mathrm{C}$.

Morphological and cultural characterization of isolates. In order to select representative isolates for molecular identification, fungal isolates from each sampling field were grouped according to the morphology of colonies on PDA and by microscopic observations of the mycelium. In particular, colonies of isolates preliminarily identified as $F$. mediterranea were differentiated into type B and S (16). Furthermore, the growth rate of selected isolates was evaluated by transferring PDA agar plugs $(5 \mathrm{~mm}$ in diameter) containing actively growing mycelium into petri dishes with PDA. Plates (three per isolate) were incubated at $24^{\circ} \mathrm{C}$ in the dark and the diameter of colonies was measured daily until complete colonization of the dish. Mean data from the experiments were analyzed for homogeneity of variance with the software package Statistics for Windows (StatSoft, Tulsa, OK) and the standard error of the mean was calculated.

Sequencing of internal transcribed spacer regions. To identify selected isolates, the internal transcribed spacer (ITS) regions of ribosomal DNA (rDNA) were amplified and sequenced. Total fungal DNA was extracted from 50 to $100 \mathrm{mg}$ of mycelium as described by Schena et al. (41) and amplified with universal primers ITS1 and ITS4 (45). Polymerase chain reactions (PCRs) were performed in a total volume of $25 \mu \mathrm{l}$ containing $100 \mathrm{ng}$ of target DNA, $2 \mathrm{mM} \mathrm{MgCl}, 0.8 \mathrm{mM}$ dNTPs, $0.4 \mathrm{mM}$ each primer, and $1 \mathrm{U}$ of Taq DNA polymerase (Eurotaq, Heidelberg, Germany). Reactions were incubated in a thermal cycler (Hybaid PCR Express; Celbio, Milan, Italy) for $3 \mathrm{~min}$ at $95^{\circ} \mathrm{C}$ followed by 40 cycles of $30 \mathrm{~s}$ at $94^{\circ} \mathrm{C}, 30 \mathrm{~s}$ at $57^{\circ} \mathrm{C}$, and $45 \mathrm{~s}$ at $72^{\circ} \mathrm{C}$. All reactions ended with a final extension of $5 \mathrm{~min}$ at $72^{\circ} \mathrm{C}$.

Amplified products were analyzed by electrophoresis and single bands of the expected size were purified with the QIAquick PCR purification kit (Qiagen, Dusseldorf, Germany) and sequenced with both forward and reverse primers by Macrogen Europe (Amsterdam). The ChromasPro version 1.5 software (http://www.technelysium.com.au/) was utilized to evaluate the quality of sequences and to create consensus sequences. Sequences of poor quality were repeated.

For isolates provisionally identified as $F$. mediterranea, alleles were determined. As a consequence, when two or more degenerate bases were identified within the consensus sequence or electropherograms continued to be unreliable after repeated resequencing, PCR fragments were cloned into competent cells of Escherichia coli using the pGEM-T Easy Vector System (Promega, Milan, Italy) according to the manufacturer's protocol. Clones were randomly selected and DNA extracted using the GenElute Plasmid Miniprep Kit (Sigma-Aldrich, St. Louis). To check insert presence and identity, plasmids were digested with EcoRI (Promega) according to the manufacturer's protocol and separated in a $1 \%$ agarose gel. For each cloned sample, six inserts were sequenced using the universal primers T7 and SP6 (pGEM-T Easy Vector System) and analyzed as described above. When more than two alleles were detected within a single cloned sample, additional clones (up to 15) were sequenced to avoid the risk of losing genetic diversity.

Molecular identification and characterization of isolates. The identity of isolates was established according to the level of homology of their ITS sequences with those of reference isolates. To this aim, sequences were aligned and compared with available sequences from previous reports $(17,35)$ using the software MUSCLE, as implemented in MEGA5 $(14,20)$. Furthermore, the Basic Local Alignment Search Tool (BLAST) was utilized to compare with sequences from the fungal barcoding project (http:// www.fungalbarcoding.org/) and GenBank (http://blast.ncbi.nlm. nih.gov/Blast.cgi).

The software ElimDupes (http://hcv.lanl.gov/content/sequence/ ELIMDUPES/elimdupes.html) was utilized to determine unique sequences and facilitate the identification of genotypes within isolates of F. mediterranea and Fomitopsis sp. Unique sequences were introduced into MEGA5 (20), aligned with MUSCLE (14), and analyzed to determine the localization of single-nucleotide polymorphisms (SNPs).

The population structure of isolates preliminarily identified as $F$. mediterranea was analyzed by generating a network of alleles with the statistical parsimony algorithm implemented in TCS ver. 1.21 (10). Sequences from reference isolates (17) were included in the analysis. Reference isolates were assumed to be all homozygous, because none of them contained degenerate bases in the GenBank deposited sequences.

Pathogenicity tests. Pathogenicity tests were conducted to confirm Koch's postulates for three representative isolates of Fomitopsis sp. (Fo1, Fo4, and Fo6) by inoculating 30-year-old lemon ('Femminello') and sour orange trees. An isolate of $F$. mediterranea from citrus (F24) and one from Vitis vinifera (Fvn) were also included in the analysis. Inoculum of all isolates was prepared using sterile wheat grains. For this, $10 \mathrm{~g}$ of grains were soaked overnight in tap water, placed on dry paper at $20^{\circ} \mathrm{C}$ for $1 \mathrm{~h}$, transferred to 100-ml Erlenmeyer flasks, and sterilized twice $\left(120^{\circ} \mathrm{C}\right.$ for $\left.20 \mathrm{~min}\right)$ on two consecutive days. Sterile grains were inoculated with fungal isolates using three mycelial plugs (diameter of $5 \mathrm{~mm}$ ) taken from the edge of actively growing colonies on PDA and incubated for 20 days at $24^{\circ} \mathrm{C}$. Flasks were vigorously shaken every 4 to 5 days to smash the mycelium and favorite the uniform colonization of grains.

For each isolate, nine branches with a diameter of $\approx 15 \mathrm{~cm}$ from three different trees were inoculated by inserting five colonized wheat grains in 2.5 -cm-deep holes ( $7 \mathrm{~mm}$ in diameter). Inoculated branches were covered with wet gauze and grafting mastic and incubated for 36 months. Branches inoculated with five sterile grains served as a control.

At the end of the incubation period, branches were transversally cut through the inoculation point in order to measure the extension of the wood area affected by rots. Data were subjected to analysis of variance and mean values were compared using Tukey's test.

To confirm Koch's postulates, attempts to reisolate the pathogen were performed with all branches from woody tissues at the margin of the decay lesion using the same procedure described above.

\section{RESULTS}

Fungal isolations. Fungal colonies were recovered from most samples, and only a single fungal taxon was found in each tree. In total, five different basidiomycetous fungi were isolated and F. mediterranea was the most common pathogen (Table 1). This basidiomycete was isolated from wood of old citrus trees in both Sicily and Apulia. However, basidiocarps were noticed almost exclusively in citrus orchards in Sicily and their presence was restricted to trees at least 35 years old. They were typically resupinate, not detachable, woody, from brown to yellowish- or grayish-brown in color, with multiple layers of context and 
hymenium, and were commonly found on trunk and scaffold branches of citrus trees as well as on trunks of declining olive trees grown as windbreaks along the borders of citrus orchards. In some orchards of Moro and Ovale sweet orange which were $>50$ years old, $>40 \%$ of the trees showed basidiocarps of $F$. mediterranea on the trunk or branches (data not shown). Another fungus identified as Fomitopsis sp. was isolated in an orchard located in Apulia from 40-year-old 'Valencia Late' sweet orange trees showing brown rot symptoms. The mycelium was white, slow growing, slightly raised, and cottony-floccose with a distinct mushroomy odor; hyphae were hyaline, thin-walled, nodose-septate, and branched. Affected trees $(\approx 20 \%$ of the total trees), showed symptoms of leaf chlorosis, twig dieback, and branch breakdown. In the incipient stage of decay, the wood showed a yellow-brown discoloration, which progressed into a wood rot. No fruiting bodies were observed. In the same orchard, other fungal isolates identified as Phellinus-like were obtained at a lower frequency from trees with white rot symptoms.

In addition to the above fungi, a few woody samples from the same orchard were found to be infected by Phellinus sp. or by a fungal taxon related to the genus Coniophora.

Identification and characterization of isolates of $F$. mediterranea. Reliable DNA sequences of the ITS regions were obtained and deposited in GenBank with accession numbers KF615708 to KF615761 (Table 1) for all isolates obtained in the present study.

An accurate identification of the isolates at the species level was possible for $F$. mediterranea by comparing sequences from the present study with sequences in GenBank and with those from reference isolates characterized by Fischer (17). A quite high level of genetic diversity was determined among isolates from citrus and between citrus and reference isolates. In all, 22 SNPs were identified across the ITS region of the 32 isolates analyzed in the present study (31 from citrus and 1 from olive) (Table 2). These SNPs differentiated 19 ITS alleles and 13 genotypes, 7 of which were heterozygous. As for isolates, 23 and 9 were homozygous and heterozygous, respectively. A higher level of heterozygosis was determined for isolates sourced in Sicily, mainly from fruiting bodies (Tables 1 and 2).
The network generated using data from the ITS sequenced data obtained in the present study along with representative sequences from Fischer (17) revealed the presence of 32 alleles differentiated by one to six steps (Fig. 1). The network showed the existence of a close correlation between representative Fischer's isolates and isolates from citrus, although a single allele (a1) was shared with an isolate from $V$. vinifera (Asti4) characterized by Fischer (17). This allele was the predominant one and was present in 21 isolates. Of these isolates, 18 were homozygous and 3 were heterozygous (Table 2). Homozygous isolates also included an isolate (Fk) obtained from an olive tree.

Surprisingly, more than two alleles were observed in two isolates based on cloning and sequencing of the amplicons. In particular, three and four alleles were found in isolates F18 and F24, respectively.

Analysis of the morphology of colonies revealed the presence of both types B and S, as defined by Fischer in 1987 (16) (Table 1). In type B (bleaching-type), the mycelial cultures were cottony to woolly with yellowish to brownish aerial hyphae, and pigmentation of the mycelium was weak or lacking. Type $\mathrm{S}$ (staining type) was characterized by a sparse development of aerial hyphae and a modest to strong pigmentation of the medium.

Isolates of $F$. mediterranea showed significant differences in terms of growth ratio on PDA plates, with colonies covering a surface of $37.4 \mathrm{~cm}^{2}$ (isolate F15) to $163.4 \mathrm{~cm}^{2}$ (isolate F11) after 2 weeks of incubation. The growth rate of isolates did not correlate to any of the investigated parameters, including geographic origin, ITS genotypes, and morphology of colonies (Fig. 2).

Identification and characterization of isolates of other lignicolous fungi. Apart from F. mediterranea, the most relevant fungus associated with citrus brown wood rots was identified as Fomitopsis sp. (Table 1). In particular, 99\% identity was found among ITS sequences of isolates from citrus and several sequences deposited in GenBank as either Fomitopsis palustris or $F$. ostreiformis. Although alleles were not determined for these isolates, the analysis of sequences enabled the identification of six SNPs, which differentiated five genotypes among the six isolates analyzed (Table 3). Furthermore, three of six sequences

TABLE 2. Nuclear genotypes and alleles (Als.) differentiated by 22 single-nucleotide polymorphisms (SNPs) among 32 isolates of Fomitiporia mediterranea based on analysis of the internal transcribed spacer (ITS) regions of ribosomal DNA

\begin{tabular}{|c|c|c|c|c|c|c|c|c|c|c|c|c|c|c|c|c|c|c|c|c|c|c|c|c|}
\hline \multirow[b]{2}{*}{ Genomes, isolates } & \multirow[b]{2}{*}{ Als. ${ }^{\mathrm{W}}$} & \multirow[b]{2}{*}{ Freq $^{\mathrm{x}}$} & \multicolumn{22}{|c|}{ SNP sites ${ }^{\mathrm{y}}$} \\
\hline & & & 190 & 498 & 499 & 511 & 512 & 518 & 519 & 542 & 543 & 583 & 610 & 626 & 634 & 640 & 649 & 655 & 675 & 676 & 698 & 701 & 702 & 737 \\
\hline $\mathrm{G} 1^{\mathrm{z}}$ & a1 & 18 & - & $\mathrm{T}$ & $\mathrm{T}$ & G & $\mathrm{A}$ & $\mathrm{G}$ & - & - & - & A & $\mathrm{T}$ & $\mathrm{T}$ & $\mathrm{T}$ & A & G & $\mathrm{A}$ & $\mathrm{C}$ & G & $\mathrm{C}$ & $\mathrm{T}$ & $\mathrm{T}$ & A \\
\hline G2 (F6) & $\mathrm{a} 2$ & 1 & - & $\ldots$ & $\ldots$ & A & $\mathrm{G}$ & - & - & - & - & $\ldots$ & $\ldots$ & $\ldots$ & $\ldots$ & $\ldots$ & $\ldots$ & $\ldots$ & $\ldots$ & $\ldots$ & $\ldots$ & $\ldots$ & $\ldots$ & $\ldots$ \\
\hline G3 (F12) & $\mathrm{a} 3$ & 1 & - & $\ldots$ & $\ldots$ & $\ldots$ & $\ldots$ & $\ldots$ & - & $\mathrm{T}$ & A & $\ldots$ & $\ldots$ & $\ldots$ & $\ldots$ & G & $\ldots$ & $\ldots$ & $\ldots$ & $\ldots$ & $\ldots$ & $\ldots$ & $\ldots$ & $\ldots$ \\
\hline \multirow[t]{3}{*}{ G4 (F18) } & a1 & 1 & - & $\ldots$ & $\ldots$ & $\ldots$ & $\ldots$ & $\ldots$ & - & - & - & $\ldots$ & $\ldots$ & $\ldots$ & $\ldots$ & $\ldots$ & $\ldots$ & $\ldots$ & $\ldots$ & $\ldots$ & $\ldots$ & $\ldots$ & $\ldots$ & $\ldots$ \\
\hline & $\mathrm{a} 2$ & $\ldots$ & - & $\ldots$ & $\ldots$ & A & $\mathrm{G}$ & $\ldots$ & - & - & - & $\ldots$ & $\ldots$ & $\ldots$ & $\ldots$ & $\ldots$ & $\ldots$ & $\ldots$ & $\ldots$ & $\ldots$ & $\ldots$ & $\ldots$ & $\ldots$ & $\ldots$ \\
\hline & $\mathrm{a} 4$ & $\ldots$ & - & $\ldots$ & $\ldots$ & $\ldots$ & $\ldots$ & - & - & - & - & $\ldots$ & $\ldots$ & $\ldots$ & $\ldots$ & $\ldots$ & $\ldots$ & $\ldots$ & $\ldots$ & $\ldots$ & $\ldots$ & $\ldots$ & $\mathrm{C}$ & $\ldots$ \\
\hline \multirow[t]{4}{*}{ G5 (F24) } & a5 & 1 & - & $\ldots$ & $\ldots$ & $\ldots$ & $\ldots$ & $\ldots$ & - & - & - & $\ldots$ & $\ldots$ & $\ldots$ & $\mathrm{C}$ & $\ldots$ & $\ldots$ & $\ldots$ & $\ldots$ & $\ldots$ & $\ldots$ & $\ldots$ & $\ldots$ & $\ldots$ \\
\hline & a6 & $\ldots$ & - & $\ldots$ & $\ldots$ & $\ldots$ & $\ldots$ & $\ldots$ & - & - & - & $\ldots$ & $\ldots$ & $\ldots$ & $\ldots$ & $\ldots$ & $\ldots$ & $\ldots$ & $\mathrm{T}$ & $\ldots$ & $\ldots$ & $\mathrm{C}$ & $\ldots$ & $\ldots$ \\
\hline & a7 & $\ldots$ & - & $\ldots$ & $\ldots$ & ... & $\ldots$ & $\ldots$ & - & - & - & $\ldots$ & $\ldots$ & $\ldots$ & $\ldots$ & $\ldots$ & A & $\ldots$ & $\mathrm{T}$ & $\ldots$ & $\ldots$ & $\ldots$ & $\ldots$ & $\ldots$ \\
\hline & $\mathrm{a} 8$ & $\ldots$ & A & $\mathrm{C}$ & $\mathrm{C}$ & A & G & - & - & $\mathrm{T}$ & A & $\ldots$ & $\mathrm{C}$ & $\mathrm{C}$ & $\ldots$ & $\ldots$ & A & $\ldots$ & $\mathrm{T}$ & $\ldots$ & $\ldots$ & $\ldots$ & $\ldots$ & $\ldots$ \\
\hline \multirow[t]{2}{*}{ G6 (F27, F34, F38) } & a1 & 3 & - & $\ldots$ & $\ldots$ & $\ldots$ & $\ldots$ & $\ldots$ & - & - & - & $\ldots$ & $\ldots$ & $\ldots$ & $\cdots$ & $\ldots$ & $\cdots$ & $\ldots$ & $\ldots$ & $\ldots$ & $\cdots$ & $\cdots$ & $\ldots$ & $\cdots$ \\
\hline & a9 & $\ldots$ & - & $\ldots$ & $\ldots$ & $\ldots$ & $\ldots$ & $\ldots$ & - & - & - & G & $\ldots$ & $\ldots$ & $\ldots$ & $\ldots$ & $\ldots$ & $\ldots$ & $\ldots$ & $\ldots$ & $\ldots$ & $\ldots$ & $\ldots$ & $\ldots$ \\
\hline \multirow[t]{2}{*}{ G7 (F31) } & a10 & 1 & - & $\ldots$ & $\ldots$ & $\ldots$ & $\ldots$ & $\ldots$ & G & - & - & $\ldots$ & $\ldots$ & $\ldots$ & $\ldots$ & $\ldots$ & $\ldots$ & $\ldots$ & $\ldots$ & $\ldots$ & $\ldots$ & $\ldots$ & $\ldots$ & G \\
\hline & a11 & $\ldots$ & - & $\ldots$ & $\ldots$ & $\ldots$ & $\ldots$ & $\ldots$ & G & - & - & $\ldots$ & $\ldots$ & $\ldots$ & $\ldots$ & $\ldots$ & $\ldots$ & $\ldots$ & $\ldots$ & $\ldots$ & $\ldots$ & $\ldots$ & $\ldots$ & $\ldots$ \\
\hline \multirow[t]{2}{*}{ G8 (F32) } & a1 & 1 & - & $\ldots$ & $\ldots$ & $\ldots$ & $\ldots$ & $\ldots$ & - & - & - & $\ldots$ & $\ldots$ & $\ldots$ & $\cdots$ & $\ldots$ & $\cdots$ & $\ldots$ & $\ldots$ & $\ldots$ & $\cdots$ & $\cdots$ & $\cdots$ & $\ldots$ \\
\hline & a12 & $\ldots$ & - & $\ldots$ & $\ldots$ & $\ldots$ & $\ldots$ & $\ldots$ & - & - & - & $\ldots$ & $\ldots$ & $\ldots$ & $\ldots$ & $\ldots$ & A & $\ldots$ & $\mathrm{T}$ & $\ldots$ & $\ldots$ & $\ldots$ & $\cdots$ & $\ldots$ \\
\hline \multirow[t]{2}{*}{ G9 (F33) } & a13 & 1 & - & $\ldots$ & $\ldots$ & $\ldots$ & $\ldots$ & $\ldots$ & - & - & - & $\cdots$ & $\cdots$ & $\cdots$ & $\cdots$ & $\cdots$ & $\cdots$ & G & $\cdots$ & $\cdots$ & $\cdots$ & $\cdots$ & $\cdots$ & $\cdots$ \\
\hline & a14 & $\ldots$ & A & $\ldots$ & $\ldots$ & A & G & - & - & $\mathrm{T}$ & A & $\ldots$ & $\ldots$ & $\ldots$ & $\ldots$ & $\ldots$ & $\ldots$ & $\mathrm{G}$ & $\ldots$ & $\ldots$ & $\ldots$ & $\ldots$ & $\ldots$ & $\ldots$ \\
\hline \multirow[t]{2}{*}{ G10 (F42) } & a15 & 1 & - & $\mathrm{C}$ & $\mathrm{C}$ & A & G & - & - & $\mathrm{T}$ & A & $\ldots$ & $\ldots$ & $\ldots$ & $\ldots$ & $\ldots$ & A & $\ldots$ & $\mathrm{T}$ & $\ldots$ & $\ldots$ & $\ldots$ & $\ldots$ & $\ldots$ \\
\hline & a16 & $\ldots$ & A & $\mathrm{C}$ & $\mathrm{C}$ & A & G & - & - & $\mathrm{T}$ & A & $\ldots$ & $\ldots$ & $\ldots$ & $\ldots$ & $\ldots$ & A & $\ldots$ & $\mathrm{T}$ & $\ldots$ & $\ldots$ & $\ldots$ & $\ldots$ & $\ldots$ \\
\hline G11 (F44) & a17 & 1 & - & $\mathrm{C}$ & $\mathrm{C}$ & A & $\mathrm{G}$ & - & - & $\mathrm{T}$ & A & $\ldots$ & $\ldots$ & $\ldots$ & $\ldots$ & $\ldots$ & $\ldots$ & $\ldots$ & $\ldots$ & $\ldots$ & $\ldots$ & $\ldots$ & $\ldots$ & $\ldots$ \\
\hline G12 (F149) & a18 & 1 & A & $\ldots$ & $\ldots$ & A & $\mathrm{G}$ & - & - & $\mathrm{T}$ & A & $\cdots$ & $\ldots$ & $\ldots$ & $\ldots$ & $\ldots$ & A & $\ldots$ & $\mathrm{T}$ & ... & $\ldots$ & $\ldots$ & $\ldots$ & ... \\
\hline G13 (F157) & a19 & 1 & - & $\ldots$ & $\ldots$ & $\ldots$ & $\ldots$ & $\ldots$ & - & - & - & G & $\ldots$ & $\ldots$ & $\ldots$ & $\ldots$ & $\ldots$ & $\ldots$ & $\ldots$ & A & $\ldots$ & $\ldots$ & $\ldots$ & $\ldots$ \\
\hline
\end{tabular}

${ }^{\mathrm{w}}$ A single allele is indicated for homozygous isolates.

${ }^{x}$ Frequency.

y Nucleotide position refers to the ITS sequence of isolate F1.

z Isolates with genotype G1: F1, F2, F3, F5, F7, F8, F9, F10, F11, F14, F15, F16, F17, F25, F35, F41, F159, and Fk. 
contained degenerate bases, indicating a heterozygous condition (Table 3).

Less clear was the identity of another group of basidiomycetous isolates (P19, P20, and P21) having affinity with the genus Phellinus. Characterized isolates shared identical ITS sequences and were significantly different if compared with all currently (December 2013) available GenBank sequences. Indeed, the highest level of identity $(96 \%)$ was found with a single ITS sequence deposited in GenBank as Phellinus mori but much lower identity $(\leq 85 \%)$ was determined with sequences of other Phellinus spp.

A single isolate obtained in the present study (P173) was identified as Phellinus sp. in light of the high identity (98 to 99\%) of its sequence with several ITS sequences deposited in GenBank as both $P$. tuberculosus and $P$. pomaceous. The identity of another isolate (Y1) remains unresolved. This isolate had a very high ITS identity (99\%) with a sequence of an uncultured fungus from polluted estuarine sediments in northern China (JX974744) but the closest sequences from identified cultured fungi had only $\approx 90 \%$ identity and belonged to different species of Coniophora.

Pathogenicity tests. Pathogenicity tests were conducted to confirm Koch's postulates for three representative isolates of Fomitopsis sp. associated with brown rot symptoms. On lemon trees, these isolates caused extended rots with symptoms identical to those observed on the naturally infected branches from which these fungi were isolated (Table 4). Interestingly, the rotted area caused by isolates Fo1 and Fo6 was significantly larger compared with that induced by isolate Fo4. Much smaller rotted areas were observed on branches inoculated with isolates of $F$. mediterranea from citrus (F24) and grape (Fvt). All inoculated fungi were reisolated from the margin of the decay lesions. Sour orange showed to be resistant in contrast to lemon. Restricted rotted areas were only observed on branches inoculated with isolate Fo1 (Table 4).

\section{DISCUSSION}

In the present study, ITS regions of the rDNA were used as barcodes for the identification of basidiomycetous fungi associated with brown and white rots of citrus wood. ITS regions have been proposed as the official fungal DNA barcode marker because they can be easily amplified and sequenced. Compared with alternative genes, they have the highest probability of successful identification for the broadest range of fungi, with the most clearly defined barcode gap between inter- and intraspecific variation (42). A major limitation in the use of ITS regions is that they can be inappropriate to differentiate phylogenetically closely related species that could have sequences which are either identical or differ by only a few nucleotide positions $(25,40)$. However, this was not the case for lignicolous fungal species recovered from rotten wood in the present study because the lack of validated sequences in public DNA databases was the main limitation to accurately identify isolates. Only isolates of Fomitiporia mediterranea were identified at the species level since this species has been clearly defined and reference isolates with corresponding ITS regions have been released $(17,18)$. Furthermore, ITS regions are variable enough to differentiate $F$. mediterranea from closely related taxa (17).

For isolates identified as Fomitopsis sp. and for an isolate (P173) identified as Phellinus sp., the lack of validated barcode sequences did not enable the identification at the species level. However, the availability in GenBank of several ITS sequences with very high identities (99\%) from different sources should have guaranteed a reliable identification of these fungi, at least at

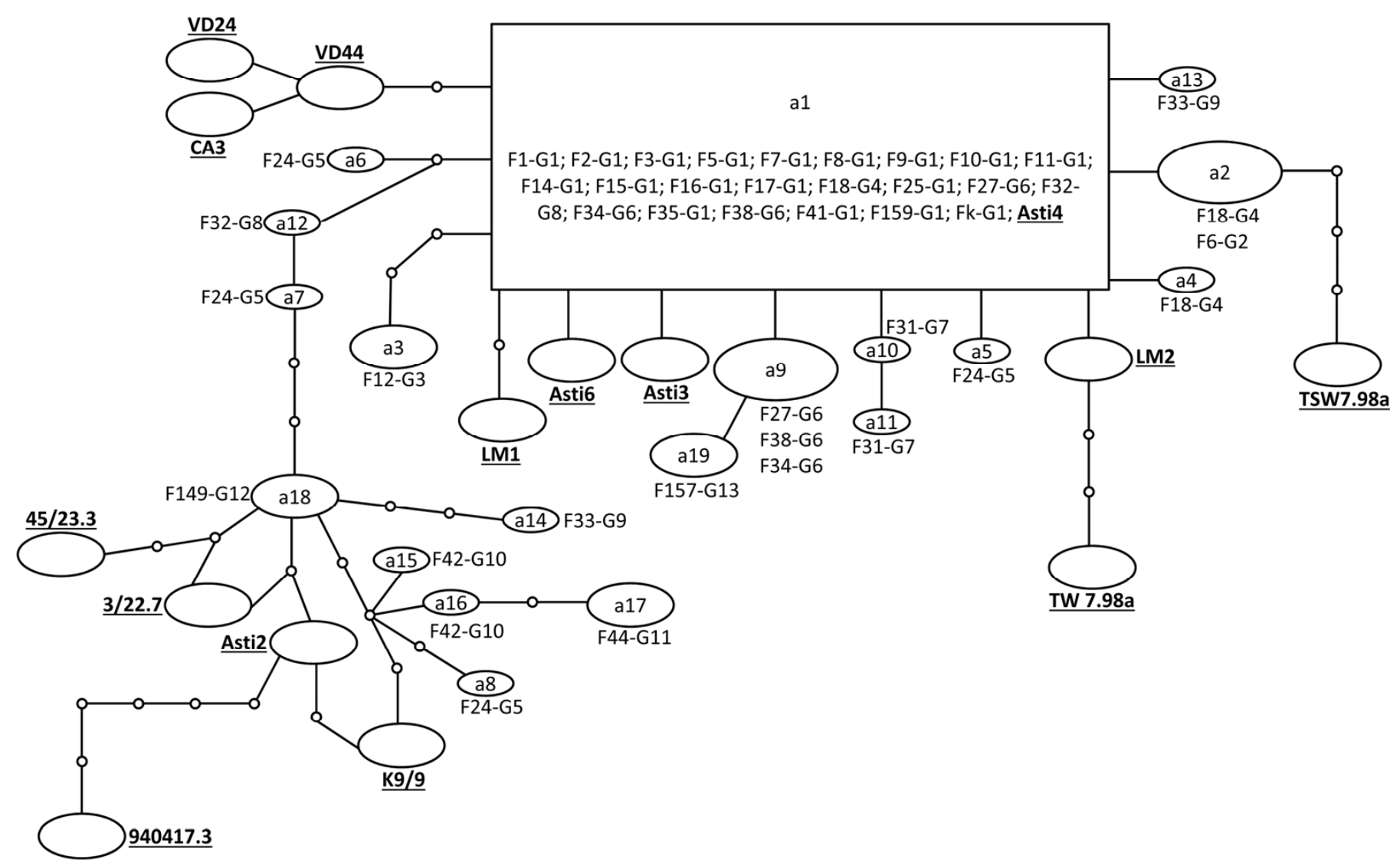

Fig. 1. Network of alleles generated using internal transcribed spacer sequences of Fomitiporia mediterranea isolates characterized in the present study along with reference isolates (bold underlined characters) from Fisher (17). The network was constructed using a statistical parsimony algorithm implemented in TCS 1.21 (10). For each allele (a), the size of each circle represents its relative frequency and the corresponding isolates are indicated outside the circle. Haplotypes were directly connected without dots when differing by a single change. Every additional putative change was indicated by adding a dot. 
the genus level. In both cases, great precaution was taken in the identification process because of unreliable annotations of sequences in public DNA repositories, which remain an obstacle to all sequence-based species identifications (33).

Other fungi isolated from citrus wood in this study were defined as Phellinus-like (P19, P20, and P21) and Coniophoralike (Y1) isolates because of lack of sequences with high identity

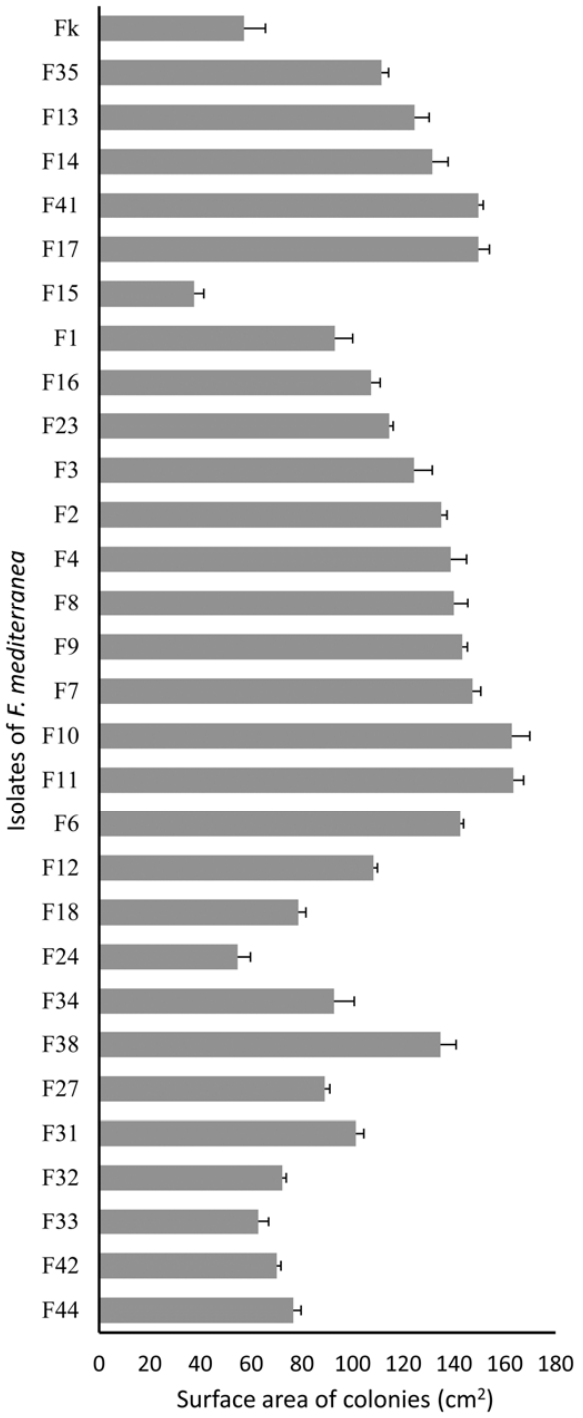

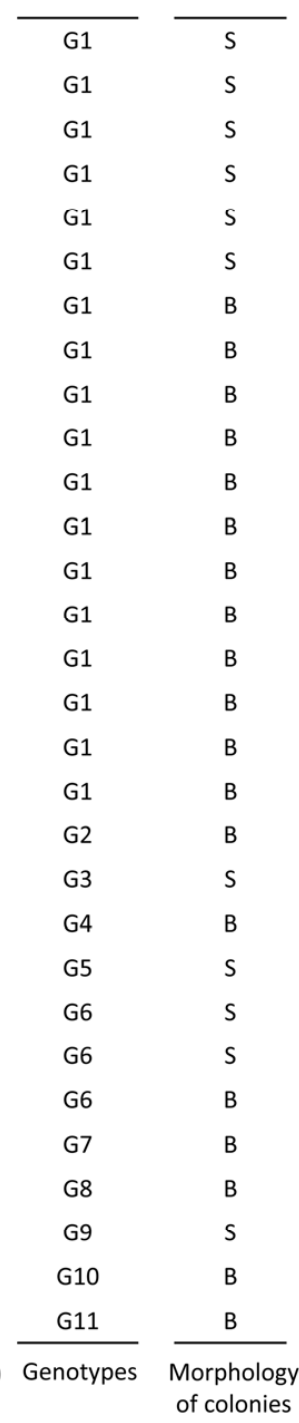

Fig. 2. Comparison between the surface area of colonies (square centimeters) of Fomitiporia mediterranea isolates on potato dextrose agar after 2 weeks of incubation at $24^{\circ} \mathrm{C}$ (left), internal transcribed spacer (ITS) genotypes (middle), and morphology of colonies as defined by Fisher (16) in types B and S (see main text). Isolates were grouped first, according to their ITS genotype; second (in each genotype), according to the morphology of colonies; and third (in each group defined by previous parameters), according to the growth rate (from low to high). Bars on the columns represent standard error of the mean. in GenBank. However, even for these fungi, ITS regions provided the most accurate identification source currently available.

The results of the present study indicate a complex etiology of citrus wood decay, with both white and brown rot fungi implicated in the disease, although white rot caused by $F$. mediterranea is the most widespread in southern Italy. The common presence of basidiocarps associated with white rot and bark cankers in old citrus orchards in Sicily could be imputed to different causes, including age of the trees and environmental conditions such as frost injuries, high humidity, and persistent shade due to close tree spacing. Furthermore, severe tree pruning and a high amount of pathogen inoculum in traditional citrus-growing areas probably play a role in favoring the disease. However, the presence of wood rot also in younger, well-managed clementine and Valencia Late orange trees in Apulia indicates that this disease is not just a problem for marginal orchards in the final part of their productive cycle. A similar conclusion was also made by Pilotti and coworkers (35) for hazelnut groves. It has been hypothesized that the presence of a high incidence of wood decay in clementine Fedele trees in Apulia is a consequence of its susceptibility to cold damage $(21,22)$.

The presence of $F$. mediterranea in various citrus-growing areas of the Mediterranean region has been documented for at least a century, although the species was identified properly only recently (15). In the present study, the analysis of ITS sequences of isolates of this basidiomycete sourced in citrus orchards of southern Italy revealed a high level of genetic variability, with 13 genotypes identified among 31 isolates examined. This finding is in agreement with previous reports $(17,35)$. In particular, Pilotti et al. (35) found a high variability within a population of $F$. mediterranea from hazelnut in a restricted geographic area in Latium region, central Italy. Among the 24 ITS sequences they provided, 16 represented unique genotypes and only 2 of them were repeated in three and seven isolates, respectively. The presence of a high level of genetic variability, even within a single field, is in agreement with the prevalent outcrossing nature of $F$. mediterranea (17). Fischer (17) also found that the development and

TABLE 4. Extension of wood rots on lemon and sour orange branches inoculated with Fomitopsis sp. (isolates Fo1, Fo4, and Fo6) or Fomitiporia mediterranea (isolates F24 and Fvt) ${ }^{\mathrm{y}}$

\begin{tabular}{lccccc}
\hline & \multicolumn{2}{c}{ Lemon } & & \multicolumn{2}{c}{ Sour orange } \\
\cline { 2 - 3 } \cline { 5 - 6 } Isolates & $\begin{array}{c}\text { Rotted area } \\
\left(\mathrm{cm}^{2}\right)\end{array}$ & $\begin{array}{c}\text { Tukey test } \\
(P \leq 0.01)\end{array}$ & & $\begin{array}{c}\text { Rotted area } \\
\left(\mathrm{cm}^{2}\right)\end{array}$ & $\begin{array}{c}\text { Tukey test } \\
(P \leq 0.01)\end{array}$ \\
\hline Fo1 & 640.3 & $\mathrm{~A}$ & & 2.7 & $\mathrm{~A}$ \\
Fo4 & 264.5 & $\mathrm{~B}$ & & 0.0 & $\mathrm{~B}$ \\
Fo6 & 662.1 & $\mathrm{~A}$ & & 0.0 & $\mathrm{~B}$ \\
F24 & 4.5 & $\mathrm{C}$ & & 0.0 & $\mathrm{~B}$ \\
Fvt & 1.0 & $\mathrm{D}$ & & 0.0 & $\mathrm{~B}$ \\
Control & 0.0 & $\mathrm{D}$ & & 0.0 & $\mathrm{~B}$ \\
\hline
\end{tabular}

${ }^{\mathrm{y}}$ Lemon and sour orange branches were inoculated by inserting wheat grains colonized by fungal isolates into the wood and incubated for 36 months. At the end of the incubation period, branches were transversally cut through the inoculation point in order to measure the extension of the wood area affected by rots.

${ }^{\mathrm{z}}$ Isolate Fvt of F. mediterranea was from Vitis vinifera.

TABLE 3. Nuclear genotypes differentiated by six single-nucleotide polymorphisms (SNPs) among six isolates of Fomitopsis sp. by analysis of the internal transcribed spacer (ITS) regions of ribosomal DNA

\begin{tabular}{|c|c|c|c|c|c|c|c|}
\hline \multirow[b]{2}{*}{ Genomes, isolates } & \multirow[b]{2}{*}{ Frequency } & \multicolumn{6}{|c|}{ SNP sites ${ }^{\mathrm{Z}}$} \\
\hline & & 122 & 127 & 129 & 132 & 175 & 391 \\
\hline G1 (Fo1) & 1 & $\mathrm{C}$ & $\mathrm{C}$ & - & $\mathrm{G}$ & $\mathrm{C}$ & $\mathrm{T}$ \\
\hline G2 (Fo3) & 1 & $\ldots$ & $\mathrm{Y}$ & - & $\ldots$ & $\mathrm{Y}$ & $\mathrm{Y}$ \\
\hline G4 (Fo2, Fo6) & 2 & $\mathrm{~T}$ & $\ldots$ & $\mathrm{T}$ & A & $\mathrm{T}$ & $\mathrm{T}$ \\
\hline G5 (Fo5) & 1 & $\mathrm{Y}$ & $\mathrm{Y}$ & $\mathrm{T}$ & A & $\mathrm{T}$ & $\mathrm{T}$ \\
\hline
\end{tabular}

${ }^{\mathrm{z}}$ Nucleotide position refers to the ITS sequence of isolate Fo1. 
growth potential of secondary mycelium were stronger in interstrain pairings than in intrastrain pairings, possibly promoting outcrossing under natural conditions. Furthermore, studies on the population structure of $F$. mediterranea indicate that this fungus is likely to be dispersed via basidiospores (11). Thus, the finding of a high percentage of heterozygous ITS genotypes (7 of 13) and isolates (9 of 31) within the citrus population analyzed in the present study was not surprising. None of the previous reports indicated the existence of ITS heterozygosity in isolates from citrus (15) or other hosts $(9,18,35,39)$.

In the present study, a higher level of heterozygosity was revealed in Sicily compared with Apulia. In the first region, the common presence of fruiting bodies within citrus orchards may have favored sexual recombination of isolates, whereas the sporadic occurrence of fruiting bodies in Apulia reduced recombination opportunities. In the latter region, cultural practices, mainly pruning, may have played a relevant role in the dissemination of the pathogen. Furthermore, it can be hypothesized that, in Apulia, the inoculum came mainly from external sources, such as abandoned woods, vineyards, and olive and fruit orchards in which the fungus might have produced fruiting bodies. In fact, $F$. mediterranea has also been isolated from many other Mediterranean plant species, including olive (7), kiwi (13), grapevine $(9,17$, 18,32), hazelnut (31), and locust tree, European privet, and plane tree (34).

An unexpected genetic background for a diploid organism such as $F$. mediterranea was determined for isolates F18 and F24 because three and four alleles, respectively, were revealed. Although most basidiomycete species form dikaryons after mating, the formation of heterokaryons with multinucleate cells is quite common in species of Agaricomycetes (mushroom-forming fungi) and may account for this result $(12,23)$. As an example, four nuclear types were found in the same mycelium of one isolate of Heterobasidion annosum (24). Furthermore, a deviation from concerted evolution in the rDNA units that would determine the presence of SNPs among the repeat units of the same isolate cannot be completely excluded.

The network of $F$. mediterranea alleles identified in the present study, along with representative sequences from Fischer (17), revealed a genetic relationship between isolates from citrus and other hosts. The largely prevalent allele (a1) in the citrus population was shared with an isolate from $V$. vinifera (Asti4) characterized by Fischer (17) and was the most common allele in a population from hazelnut, representing 7 of 24 isolates (35).

The in vitro growth rate of $F$. mediterranea isolates from citrus showed variability even for isolates from the same locality. Similar results were determined for $F$. mediterranea isolates from hazelnut (35). The growth rate of isolates was not correlated with other evaluated parameters, including genotype and morphology of the colonies. Specific pathogenicity tests would be necessary to find out whether any of these parameters is correlated with virulence.

Apart from $F$. mediterranea, a relevant lignicolous fungus associated with brown wood rot in orange trees that was described previously by us (37) was identified as Fomitopsis sp. The analysis of ITS sequences revealed the presence of six SNPs differentiating five genotypes within the six isolates analyzed. This very limited number of isolates suggests the existence of a high level of variability among citrus isolates, considering that they all came from the same field and that fruiting bodies of the fungus were not observed. It is possible that inoculum of the fungus was produced on basidiocarps on alternative surrounding hosts and was disseminated by wind to citrus. Fomitopsis spp. commonly infect conifers and hardwoods (38), including apple, pear, plum, cherry, and peach (2). Sunburn of branches and large wounds after heavy pruning through which the pathogen gained entrance could have been predisposing factors to such severe infections (37).
Pathogenicity tests showed a very high virulence of Fomitopsis sp. on lemon branches whereas sour orange was found to be resistant to Fomitopsis sp. and F. mediterranea, confirming our field observations (data not shown) and results of previous experiments conducted with the latter fungus (15). On inoculated lemon branches, the rots caused by Fomitopsis sp. were much more extensive compared with those caused by $F$. mediterranea, although a significant difference in virulence also was revealed among the three isolates of Fomitopsis sp. The rapid colonization of wood by Fomitopsis sp. was expected, considering that white rot fungi degrade all cell wall components, including lignin, whereas brown rot fungi depolymerize cellulose rapidly during incipient stages of wood colonization. The limited extension of rots caused by $F$. mediterranea on citrus wood confirms results of previous experiments conducted on grape (27) and is in agreement with its prevalent presence only on old citrus trees. Similarly, the rapid development of brown rot caused by Fomitopsis $\mathrm{sp}$. is in agreement with the serious damage caused by the fungus in a middle-aged citrus orchard. Although Fomitopsis sp. does not seem to represent a common risk for citrus orchards, the results of the present study suggest that it can locally cause serious damage, probably in relation to particular microenvironmental conditions and the abundance of inoculum.

Other fungal isolates obtained from trees with white rot symptoms were identified as Phellinus sp. and Phellinus-like. Species of the genus Phellinus are widely known as wood-rotting fungi, mainly of forest trees, but they are rarely reported on citrus. Further investigations are needed for species identification and to determine the geographic distributions and role in citrus wood rot.

Another occasionally isolated fungus from clementine trees with brown rot symptoms was identified as a Coniophora-like fungus. Coniophora eremophila has been reported as the most important fungus associated with brown heartwood rot in citrus plants in the United States $(3,30,31)$, although the identity of the fungus at the species level was questioned based on restriction fragment length polymorphism and random amplified polymorphic DNA analyses (1). It is possible that the fungus isolated in Italy is the same one characterized in United States; however, the lack of GenBank ITS sequences from this species and the absence of basidiocarps in Italy did not enable the confirmation of this hypothesis. To the best of our knowledge, this is the first report of a Coniophora-like fungus causing wood rot on citrus in Europe.

In conclusion, a complex etiology was revealed for citrus wood rot in southern Italy, with different basidiomycetous fungi implicated in the disease. The accurate identification of these causal agents and the comprehension of their epidemiology is an essential prerequisite to attempt any possible control strategy.

\section{ACKNOWLEDGMENTS}

This work was partially funded by MIUR-FIRB 2010 "Metagenomic strategies to assess genetic diversity in soil-borne Phytophthora species" and by Project "SAMAGRUMI, Sensori Ambientali per il miglioramento della qualità delle produzioni agrumicole, PO FESR 2007/2013, Asse IV, Obiettivo Operativo 4.1.1, Linea di intervento 4.1.1.2-Decreto di ammissione n. 626/3 del 17/02/2012".

\section{LITERATURE CITED}

1. Adaskaveg, J. E., Förster, H., Mauk, P. A., Bigelow, D. M., and Gilbertson, R. L. 2001. Molecular characterization of Coniophora isolates from citrus in Arizona and California. Harvard Pap. Bot. 6:15-23.

2. Adaskaveg, J. E., Miller, R. W., and Gilbertson, R. L. 1993. Wood decay, lignicolous fungi, and decline of peach trees in South Carolina. Plant Dis. 77:707-711.

3. Adaskaveg, J. E., and Ogawa, J. M. 1990. Wood decay pathology of fruit and nut trees in California. Plant Dis. 74, 341-352.

4. Bigelow, D. M., Gilbertson, R. L., and Matheron, M. E. 1998. Cultural studies of fungi causing brown rot in heartwood of living lemon trees in Arizona. Mycol. Res. 102:257-262. 
5. Bigelow, D. M., Matheron, M. E., and Gilbertson, R. L. 1996. Biology and control of Coniophora eremophila on lemon trees in Arizona. Plant Dis. 80:934-939.

6. Butin, H. 1995. Tree Diseases and Disorders. Oxford University Press, Oxford.

7. Carlucci, A., Lops, F., Raimondo, M. L., Gentile, V., Colatruglio, L., Mucci, M., and Frisullo, S. 2008. Comportamento patogenetico di alcuni isolati fungini associati a striature brune del legno di olivo. Petria 18:15-25.

8. Childs, J. F. L. 1952. Concentric canker and wood rot of citrus associated with Fomes applanatus in Florida. Phytopathology 43:99-100.

9. Ciccarone, C., Graniti, A., Schiaffino, A., and Marras, F. 2004. Molecular analysis of Fomitiporia isolates from esca-affected grapevines in southern Italy. Phytopathol. Mediterr. 43:268-272.

10. Clement, M., Posada, D., and Crandall, K. A. 2000. TCS: a computer program to estimate gene genealogies. Mol. Ecol. 9:1657-1660.

11. Cortesi, P., Fischer, M., and Milgroom, M. G. 2000. Population diversity of Fomitiporia punctata from grapevine and spread of esca disease. Integrated control in viticulture IOBC/wprs Bull. 23:71-73.

12. de Fine Licht, H. H., Andersen, A., and Aanen, D. K. 2005. Termitomyces sp. associated with the termite Macrotermes natalensis has a heterothallic mating system and multinucleate cells. Mycol. Res. 109:314-318.

13. Di Marco, S., Calzarano, F., Osti, F., and Mazzullo, A. 2004. Pathogenicity of fungi associated with a decay of kiwifruit. Australas. Plant Pathol. 33:337-342.

14. Edgar, R. C. 2004. MUSCLE: multiple sequence alignment with high accuracy and high throughput. Nucleic Acids Res. 32:1792-1797.

15. Elena, K., Fischer, M., Dimou, D., and Dimou, D. M. 2006. Fomitiporia mediterranea infecting citrus trees in Greece. Phytopathol. Mediterr. 45:35-39.

16. Fischer, M. 1987. Biosystematische Untersuchungen an den Porlingsgattungen Phellinus Quél. und Inonotus Karst. Bibl. Mycol. 107:1-133.

17. Fischer, M. 2002. A new wood-decaying basidiomycete species associated with esca of grapevine: Fomitiporia mediterranea (Hymenochaetales). Mycol. Prog. 1:315-324.

18. Fischer, M. 2006. Biodiversity and geographic distribution of basidiomycetes causing esca-associated white rot in grapevine: a worldwide perspective. Phytopathol. Mediterr. 45:30-42.

19. Futch, S. H., Graham, J. H., Duncan, L. W., and Timmer, L. W. 2006. Ganoderma wood-rotting fungi on citrus stumps. http://edis.ifas.ufl. edu/hs269

20. Hall, B. G. 2013. Building phylogenetic trees from molecular data with MEGA. Mol. Biol. Evol. 30:1229-1235.

21. Ippolito, A., and Nigro, F. 1993. Osservazioni su un caso di carie in piante di agrumi. Micol. Ital. 3:9-12.

22. Ippolito, A., Nigro, F., and Decock, C. 1998. Phellinus punctatus, agente di carie in piante di agrumi. Inf. Fitopatol. 12:36-40.

23. James, T. Y., Stenlid, J., Olson, A., and Johannesson, H. 2008. Evolutionary significance of imbalanced nuclear ratios within heterokaryons of the basidiomycete fungus Heterobasidion parviporum. Evolution 62:2279-2296.

24. Johannesson, H., and Stenlid, J. 2004. Nuclear reassortment between vegetative mycelia in natural populations of the basidiomycete Heterobasidion annosum. Fungal Genet. Biol. 41:563-570.

25. Kiss, L. 2012. Limits of nuclear ribosomal DNA internal transcribed spacer (ITS) sequences as species barcodes for Fungi. Proc. Natl. Acad. Sci. USA 109:E1811.

26. Knorr, L. C. 1973. Pages 103-105 in: Citrus Diseases and Disorders. University Presses of Florida, Gainesville.

27. Laveau, C., Letouze, A., Louvet, G., Bastien, S., and Guerin-Dubrana, L.
2009. Differential aggressiveness of fungi implicated in esca and associated diseases of grapevine in France. Phytopathol. Mediterr. 48:32-46.

28. Lonsdale, D. 1999. Principles of tree hazard assessment and management. In: Research for Amenity Trees 7. The Stationery Office, London

29. Magnano Di San Lio, G., 2012. Malattie fungine. Pages 246-265 in: Gli agrumi. E. Tribulato and P. Inglese, eds. Bayer Crop Science, Script, Bologna, Italy.

30. Matheron, M. E., Gilbertson, R. L., and Matejka, J. C. 1992. Coniophora sp. implicated in rapid development of wood rot on living branches of lemon trees in Arizona. Phytopathology 82:1083.

31. Matheron, M. E., Porchas, M., and Bigelow, D. M. 2006. Factor affecting the development of wood rot lemon trees infected with Antrodia sinuosa, Coniophora eremophila, and a Nodulisporium sp. Plant Dis. 90:554-558.

32. Mugnai, L., Graniti, A., and Surico, G., 1999. Esca (black measles) and brown wood streaking: two old and elusive diseases of grapevines. Plant Dis. 83:404-418.

33. Nilsson, R. H., Ryberg, M., Kristiansson, E., Abarenkov, K., Larsson, K. H., and Koljalg, U. 2006. Taxonomic reliability of DNA sequences in public sequence databases: a fungal perspective. PLoS One 1:e59.

34. Pilotti, M., Gervasi, F., and Brunetti, A. 2005. Molecular identification of Fomitiporia mediterranea and Eutypa lata/Libertella blepharis in Platanus acerifolia. J. Phytopathol. 153:193-202.

35. Pilotti, M., Tizzani, L., Brunetti, F., Gervasi, G., Di Lernia, G., and Lumia, V., 2010. Molecular identification of Fomitiporia mediterranea on declining and decayed hazelnut. J. Plant Pathol. 92:117-131.

36. Reichert, I. 1932. A new root rot of citrus in Palestine. Hadow 5:254-256.

37. Roccotelli, A., Schena, L., Sanzani, S. M., Cacciola, S. O., and Ippolito, A. 2010. Fomitopsis sp. causing brown rot in wood of living citrus trees reported for first time in Southern Italy. New Dis. Rep. 22:13.

38. Ryvarden, L., and Gilbertson, R. L. (eds.) 1993. European polypores, Vol. 1. Lubrecht \& Cramer Ltd., Oslo, Norway.

39. Sánchez-Torres, P., Hinarejos, R., González, V., and Tuset, J. J. 2008. Identification and characterization of fungi associated with esca in vineyards of the Comunidad Valenciana (Spain). Span. J. Agric. Res. 6:650-660

40. Schena, L., Mosca, S., Cacciola, S. O., Faedda, R., Sanzani, S. M., Agosteo, G. E., Sergeeva, V., and Magnano di San Lio, G. 2013. Species of the Colletotrichum gloeosporioides and $C$. boninense complexes associated with olive anthracnose. Plant Pathol. Online publication. doi: $10.1111 /$ ppa. 12110

41. Schena, L., Nigro, F., and Ippolito, A. 2002. Identification and detection of Rosellinia necatrix by conventional and real-time Scorpion-PCR. Eur. J. Plant Pathol. 108:355-366.

42. Schoch, C. L., Seifert, K. A., Huhndorf, S., Robert, V., Souge, J. L., Lévesque, C. A., Chen, W., and Fungal Barcoding Consortium. 2012. Nuclear ribosomal internal transcribed spacer (ITS) region as a universal DNA barcode marker for Fungi. Proc. Natl. Acad. Sci. USA 109:62416246.

43. Skaria, M., and Farrald, C. 1989. Biological and cultural factors associated with citrus replant problems in Texas. (Abstr.) Phytopathology 79:1193

44. Skaria, M., Smith, G. S., and Gilbertson, R. L. 1990. Root rot of young citrus caused by a species of Ganoderma lucidum complex. (Abstr.) Phytopathology 80:974.

45. White, T. J., Bruns, T., Lee, S., and Taylor, J. 1990. Amplification and direct sequencing of fungal ribosomal RNA genes for phylogeneties. Pages 315-322 in: PCR Protocols. A Guide to Methods and Applications. M. A. Innis, D. H. Gelfand, J. J. Sninsky, and J. W. White, eds. Academic Press, New York. 